\title{
PENERAPAN PEMBELAJARAN TARI SITALASARI MELALUI MEDIA AUDIO VISUAL PADA SISWA SEKOLAH MENENGAH PERTAMA (SMP) BINTANG LANGKAT
}

\author{
FACHRUNNISA
}

Prodi Pendidikan Tari

\begin{abstract}
Abstrack
This study aimed to describe the application of learning and the result of learning Sitalasari dance through audio visual on students at Bintang Langkat junior high school. In this discussion using the theories related to research topics such as audio visual theory and the result of learning. The method used quantitative methods. Population in the course of a study as well as an example of a study Bintang Langkat junior high school. The data collection technique consisted of field observation and test. Based on this study, it can be seen that through the audio visual media student the result of learning in the material in class VII Sitalasari Bintang Langkat Junior high school. Ratings were used in this study is the assessment of psychomotor (skill) and attitude. In psychomotor assessment results obtained after the study is fairly good student the result of learning, namely the amount of the average value of students reached $75.5 \%$ of students who achieve mastery of 25 people and students who do not achieve mastery of 5 people. The result are considered sufficient because it meet the of specified benchmark by $83.33 \%$ of student who complete and $16.66 \%$ of students who do not achieve mastery. Assessment of student the result of learning with attitudes, values, excellent students there are eight people, the percentage was $26.67 \%$ of students with good people grades there are 17 people, the percentage is $56.66 \%$ on sufficent student score 5 people percentagenya is 16.67 .
\end{abstract}

Keyword : Audio Visual Learning 


\section{PENDAHULUAN}

Pendidikannasionalbertujuan

untukmencerdaskankehidupanbangsa danmengembangkanmanusia

Indonesia seutuhnya, yaitumanusia yang

berimandanbertaqwaterhadapTuhan

Yang MahaEsadanberbudipekerti, luhur,

memilikipengetahuandanketerampila

n,

kesehatan,

kesehatanjasmanidanrohani,

kepribadian

yang

mantapmandiriserta

rasa

tanggungjawabkemasyarakatandanke

bangsaan.

Pendidikanmerupakanusaha yang

dilakukansecarasadarolehsemuaelem

en yang adadisekitarkehidupankita,

baikitu orang tua, keluarga, sahabat, ataupunmasyarakatsecaraumumsertal embaga-lembagapendidikanbaik

yang resmidan formal yang

dibentukolehpemerintahdanpihak

yang bertanggungjawab di Indonesia, ataupunlembaga-lembaganonformal.

Pendidikanitu di dalamnyaadasuatu proses

Pembelajaranadalah pembelajaran. interaksipesertadidikdenganpendidik dansumberbelajarpadasuatulingkung

anbelajar yang meliputi guru

dansiswa

yangsalingbertukarinformasi

Pembelajaranjugammpunyaitujuanya ituperilakuhasilbelajar yang diharapkanterjadi, dimiliki, ataudikuasaiolehpesertadidiksetelah mengikutikegiatanpembelajaranterte ntu.

Agar

penelitianberfokuspadasatumasalah yang akanditinjaulebihlanjut. Makaperumusanmasalahdalampeneli tianiniadalahsebagaiberikut: "Bagaimanabentukpenerapanpembel ajarantariSitalasarimelalui media Audio Visual pada siswaSekolahMenengahPertama

(SMP)BintangLangkat?"

Pembelajaranjugatidakterlepas

dari media sebagaipenunjangtercapainyatujuanp embelajaran.Melalui media, seorang guru sangatterbantudalam proses belajarmengajar. Media adalahsegalabentukdansaluran yang digunakanuntukmenyampaikaninfor masiataupesan.Kata media berasaldari kata "medium".Secaraharfiah kata 
tersebutmempunyaiarti "perantara", yaituperantarasumberpesan $\quad(a$ source) denganpenerimapesan (a receiver).Jadi, dalampengertian yang lain, media adalahalatuntukmeyampaikanpesand arikomunikatorkepadakhalayak. Ada banyak media yang bisaseorang guru gunakansebagaialatbantu yang mempermudah proses belajarmengajar, salahsatunyaadalah media audio visual. Pengertian media audio visual adalah media yang mempunyaiunsursuaradanunsurgamb ar.Jenis media inimempunyaikemampuan yang lebihbaik, karenameliputikeduajenis media auditif (mendengar) dan visual (melihat). Media audio visual merupakansebuahalatbantu audio visual yang berartibahanataualat yang

dipergunakandalamsituasibelajaruntu kmembantutulisandan kata yang diucapkandalammenularkanpengetah uan, sikap, dan ide.

SekolahMenengahPertama (SMP) merupakanjenjangpendidikandasar formal setelahmenyelesaikanpendidikanSek
olahDasar (SD) atau yang sederajat.Sekolah Menengah Pertamadilaksanakandalamkurunwak tu 3 tahun, mulaikelas 7 sampaikelas 9.Salah satubidangstudi yang diajarkanpadapendidikandasartingkat Sekolah Menengah PertamadiantaranyapendidikanSeniB udaya, yang di dalamnyatercakupsenirupa, senitari, seniteater, dansenimusik.PendidikanSeniBuday abertujuanuntukmeningkatkanapresia sisenidanbudaya yang ada di Indonesia.Selainitu, pendidikanSeniBudayajugasebagai proses pembentukanpribadi yang terampildanmemilikibekalkemampua ndibidangseni (Mulyana, 2009: 274). Dalamkelassenibudaya, khususnyasenitarihanyamemilikiwak tu $2 \quad \mathrm{x}$ 40menitdalamseminggu.Sedangkanp embelajaransenitarisangatmembutuh kanwaktu yang lebihbanyakuntukmelakukanpraktek tari. Di dalam satu semester ada 3 materi tari yang dipelajari, tetapi pada pembelajaran melalui media audio visual ini hanya menguji satu materi tari 
saja.Dikarenakanpembelajaransenitar itidakhanyamelaluiteorisaja, tetapidalampembelajaransenitariini, seorang guru

membutuhkanwaktupraktek agar tercapainyatujuanpembelajaran.Senit arijugamenggunakantubuhsebagai media.Selain itupemakaianruangkelas yangkurangefektifuntukmelakukanpr aktektari,karena ruanggeraksiswasiswamenjaditerbatas.

Dalampembelajaransenitari

guru

seringmenemukanpermasalahandala

$\mathrm{m}$ proses

pembelajarantariyaitukurangnyakem auansiswadalammenarikantaridaerah denganteknik-teknik yang benar. Sehinggabanyaksiswa yang memperolehnilai yang rendahdanbelummencapaisecaramak simalnilai KKM (KriteriaKetuntasan Minimal) $75 \quad$ (tujuhlima). Dalampembelajaransenitari, siswasiswiSekolahMenengahPertamamemi likidayaserap yang berbeda-beda, sebagiansiswa-

siswimempunyaidayaserap yang cepat, sedang, dankurang.Keadaaniniterjadidisebab
kanolehbeberapafaktor.Pertama, ialahfaktorsiswa.Biladipandangdaris udutpandangsiswaantaralainkurangn yaminatsiswadalampembelajaranseni tari,

kurangnyakonsentrasisiswadalampe mbelajaransenitari. Disisilain, faktorkeduaialah guru. Biladipandangdarisudutpandang guru sebagaisumberbelajar, makafaktornyaialahkurangnyaketera mpilan guru dalammelakukanvariasipenyampaian materipelajaran, terutamadalampemanfaatandanpengo lahan media pembelajaran.Kemudianfaktorsarana danprasaranadidugajugaturutmenyeb abkanhasilbelajarsiswarendahyaknik urangnya media ataualat bantu yang digunakansebagai proses penunjangdalamkegiatanbelajarmeng ajarsiswaselama di kelas. Sebagaiseorang guru kitadapatmenggunakan media audio visual

sebagaialatbantuuntukmempermudah siswadalammengingatsebuahpembela jarantari. Sehinggamateri yang dibawakandapattersampaikandengan alokasiwaktu 2 x 40menitdalam 1 
(satu)

kali

pertemuandengansistempenilaian

yang terdiridariwiraga

(kemampuanataukemahiransiswaunt

ukmembawakangerakansitalasarisesu

aidengankwalitasgerak yang

yangbenar),

wirama

(kemampuansiswadalammengikutipe

ngaturan tempo musik yang

dipakaisebagaiiringantari), wirasa

(suatukemampuanataukemahiransisw

adalammenghayatimakna yang

terkandungdalamtarisitalasari).

Oleh karena itu, maka penulis tertarik untuk menjadikan Tari Sitalasaridalam kajian penelitiannya dengan judul "Penerapan Pembelajaran Tari Sitalasari Melalui Media Audio Visual pada Siswa Sekolah Menengah Pertama (SMP) Bintang Langkat.

Tujuan yang ingin dicapai dalam penelitian ini adalah sebagai berikut:

1. Mendeskripsikan

carapembelajarantariSitalasarimel alui media audiovisual pada siswa

Sekolah Menengah Pertama

Bintang Langkat.

2. Mendeskripsikanhasilbelajarsenita rimelalui media audio visual pada
siswaSekolahMenengahPertamaB

intangLangkat

\section{Landasan Teoritis}

Untuk membahas Penerapan Pembelajaran Tari Sitalasari Melalui Media Audio Visual Pada Siswa Sekolah Menengah Pertama (SMP) Bintang Langkatpenulis menggunakan beberapa teori yaitu teori media audio visual, teori hasil belajar, pengertian penerapan pembelajaran.

\section{Lokasi dan Waktu Penelitian}

Sesuai dengan judul penelitian "Penerapan Pembelajaran Tari Sitalasari Melalui Media Audio Visual Untuk Meningkatkan Hasil Belajar Seni Tari Siswa Sekolah Menengah Pertama Bintang Langkat, maka tempat penelitian adalah di Sekolah Menengah Pertama Bintang Langkat, Desa Ara Condong, Kec. Stabat Kabupeten Langkat. Penelitian akan dilaksanakan dari awal Januari 2015 sampai Maret 2016. Akan tetapi, sebelum penelitian dilakukan, peneliti sudah melakukan observasi untuk mencari informasi mengenai topik 
permasalahan dan memastikan materi tari yang akan diteliti.

\section{Populasi dan Sampel}

\section{Populasi}

Populasi dalam penelitian ini adalah siswa Sekolah Menengah Pertama Bintang Langkat kelas 7A.

\section{Sampel}

Sampel dalam penelitian ini adalah siswa-siswi kelas 7A Sekolah Menengah Pertama Bintang Langkat, Kabupaten Langkat yang berjumlah 30 orang.

\section{Teknik Pengumpulan Data}

Teknik pengumpulan data yang dilakukan adalah sebagai berikut:

1. Observasi Lapangan

2. Studi Kepustakaan

3. Dokumentasi

4. Tes Praktek Tari

\section{Teknik Analisis Data}

Dalam penelitian ini data yang digunakan adalah analisis deskriptif kuantitatif dimana penelitian ini sesuai dengan fakta sosial dan memberi gambaran, keterangan serta uraian.

ISI

Pembelajaran Sitalasari melalui media audio visual untuk siswa Sekolah Menengah Pertama (SMP) Bintang Langkat dilakukan dalam dua kali pertemuan. Dalam pembelajaran tari Sitalasari, penulis bertindak sebagai peneliti, pembelajaran dilakukan oleh guru bidang studi. Sebelum melakukan pembelajaran melalui audio visual, penulis melakukan pre-tes untuk melihat bagaimana pembelajaran tari siswa sebelumnya. Penilaian pre-tes dilakukan oleh penulis yang dibantu oleh guru seni budaya, nilai rata-rata siswa pada penilaian pre-tes dibawah KKM (Kriteria Ketuntasan Minimum) 75 (tujuh lima). Pada pembelajaran tari melalui media audio visual ini penulis bekerjasama dengan guru dan penulis menyediakan fasilitas audio visual untuk proses pembelajaran. Penulis mengamati dan menilai hasil belajar praktek tari siswa melalui media audio visual yang telah diberikan. Penulis menilai hasil belajar siswa 
dengan aspek penilaian yaitu: wiraga, wirama, dan wirasa.

Pada pertemuan pertama, langkah pertama yang dilakukan pada pembelajaran Sitalasari melalui media audio visual ini adalah guru memperkenalkan penulis kepada siswa-siswi Sekolah Menengah Pertama (SMP) yang berada di kelas 7A, kemudian siswa-siswi juga memperkenalkan dirinya satu persatu kepada penulis. Setelah perkenalan dilakukan di dalam kelas, penulis menjelaskan tentang tari Sitalasari yang akan menjadi materi pembelajaran tari melalui media audio visual. Penulis juga menceritakan isi dari tari Sitalasari yang bercerita tentang rindunya kampung halaman dan sekaligus menjelaskan bahwa tari Sitalasari berasal dari daerah Simalungun Sumatera Utara.

Dalam pembelajaran tari Sitalasari metode yang digunakan untuk tercapainya tujuan pembelajaran adalah metode demonstrasi yang menggunakan alat bantu audio visual. Dimana media audio visual ini adalah media yang mempunyai kemampuan lebih baik, karena meliputi kedua jenis media auditif (mendengar) dan visual (melihat). Media audio visual juga merupakan sebuah alat bantu audio visual yang berarti bahan atau alat yang dipergunakan dalam situasi belajar. Media audio visual ini mempunyai peranan yang sangat penting dalam proses pembelajaran. Pada pembelajaran seni budaya siswa-siswi belajar dengan praktek terbimbing, tetap dalam bimbingan guru bidang studi Seni Budaya. Dalam Pembelajaran seni tari diperlukan media audio visual agar materi tari yang diberikan dapat tercapai sesuai tujuan pembelajaran yang di inginkan. Pembelajaran dengan menggunakan media audio visual dapat meningkatkan apresiasi siswa, kreativitas siswa dan meningkatkan ketertarikan siswa dalam pelajaran seni tari.

Pada pembelajaran seni budaya khususnya seni tari dengan materi tari Sitalasari penulis mempersiapkan fasilitas infocus dan VCD pembelajaran tari Sitalasari serta memberikan apresiasi dengan memutarkan VCD pembelajaran tari. Setelah guru seni budaya 
memutarkan video pembelajaran tari Sitalasari tersebut, siswa-siswi mulai bertanya tentang tari Sitalasari yang akan menjadi materi pembelajaran. Guru seni budaya mulai membagikan kelompok. Dalam satu kelas ada 30 siswa, guru seni budaya membagikan 3 kelompok yang berisikan 10 orang. Lalu guru seni budaya memilih salah satu diantara kelompok sebagai tutor sebaya. Pemilihan kelompok dilakukan berdasarkan kemampuan siswa. Siswa yang dianggap mempunyai kemampuan lebih yang dijadikan tutor sebaya dalam kelompok, maka tutor sebaya diharapkan bisa membantu guru seni budaya dalam proses pembelajaran. Pada kegiatan inti ini, siswa-siswi mulai mengeksplorasi gerak-gerak dasar tari Sitalasari melalui media audio visual.

\section{Pembelajaran dengan} menggunakan media audio visual adalah solusi bagi guru karena keterbatasan waktu dalam pembelajaran tari. Pembelajaran tari di sekolah kurang mendapat tempat, dikarenakan pembelajaran seni tari tergabung dalam seni budaya, yang didalamnya mencakup seni rupa, seni tari, seni teater dan seni musik. Pembelajaran seni tari di sekolah hanya 2 x 40 menit dalam satu minggu, sedangkan untuk melakukan praktek tari membutuhkan waktu yang lebih lama. Pembelajaran seni tari disekolah dianggap kurang efektif dan efisien karna keterbatasan waktu. Untuk pembelajaran tari ini, target yang diharapkan hanya dalam 2 kali pertemuan sesuai dengan yang dituangkan dalam RPP yang terlampir pada bagian lampiran. Dengan adanya media audio visual ini sebagai alat bantu pembelajaran kepada siswa yang kurang memahami pembelajaran tari, kurang mampu menggerakkan tubuh seseuai teknik yang benar, dan kurang mampu mengafal dengan mudah. Pembelajaran dengan menggunakan alat bantu audio visual ini banyak membantu siswa dalam proses belajar menari, mempermudah proses pembelajaran disekolah, dan siswa-siswi bisa mengulang dan mempelajarinya lagi dirumah.

Pertemuan kedua pada pembelajaran tari Sitalasari siswasiswi melanjutkan pembelajaran praktek tari yang didapat pada 
pertemuan sebelumnya, siswa-siswi mengulang motif-motif gerak tari Sitalasari yang telah dipelajari atau dipraktekkan dirumah secara berkelompok dengan menggunakan audio visual berupa VCD pembelajaran tari Sitalasari yang telah diberikan oleh penulis kepada masing-masing kelompok. Dalam pertemuan ini, guru melihat bagaimana cara kerja siswa-siswi pada tari Sitalasari melalui media audio visual.

Pada pertemuan ketiga, penulis dibantu guru seni budaya melakukan penilaian hasil belajar siswa-siswi yang telah dilakukan dalam $2 \mathrm{x}$ pertemuan melalui tugas yang telah diberikan. Penulis mengamati dan mengambil nilai pada setiap kelompok. Perubahan hasil belajar siswa-siswi dengan menggunakan media audio visual jauh lebih baik, karena siswa lebih mampu menggerakkan tubuh sesuai teknik tari Sitalasari dengan benar. Siswa-siswi juga mampu bekerja sama dalam kelompok untuk mempelajari tarian yang diberikan. Dengan adanya tutor sebaya sebagai contoh dalam kelompok yang sangat membantu siswa-siswi lain yang kurang memahami pembelajaran tari.Penilaian praktek tari melalaui media audio visual yang telah diberikan kepada masing-masing kelompok dengan penguasaan teknik tari yaitu wiraga, wirama, wirasa. Indikator penilaian wiraga adalah dapat menggerakkan kaki sesuai dengan teknik tari Sitalasari, dapat menggerakkan tangan sesuai dengan teknik tari Sitalasari, dapat menggerakkan badan sesuai dengan teknik tari Sitalasari, dapat menggerakkan kepala sesuai dengan teknik tari Sitalasari, dan dapat mengordinasikan antar gerak tari Sitalasari dengan teknik yang benar. Serta mampu menghafal gerakkan yang ada pada tari Sitalasari. Penilaian kedua adalah wirama, indikator penilaiannya adalah mampu bergerak dengan tempo sesuai musik iringan. Penilaian ketiga adalah wirasa, indikator penilaiannya adalah mampu menghayati isi pada tari Sitalasari dan mengekspresikannya lewat mimik wajah. Penilaian dilakukan dalam bentuk persentase. Penilaian wiraga persentasenya adalah $50 \%$, 
persentase penilaian wirama $30 \%$ dan persentase penilaian wirasa $20 \%$. Penilaian bukan hanya psikomotorik (keterampilan) saja, namun ada penilaian sikap yang mencakup nilai: $\mathrm{A}=$ Sangat Baik, $\mathrm{B}=$ Baik, $\mathrm{C}=$ Cukup, D = Kurang.

\section{Hasil Belajar Praktek Tari}

Hasil belajar adalah suatu hasil nyata yang dicapai oleh siswa dalam usaha menguasai kecakapan jasmani dan rohani disekolah yang diwujudkan dalam bentuk raport pada setiap semester. Untuk mengetahui perkembangan sampai di mana hasil yang telah dicapai oleh seseorang dalam belajar, maka harus dilakukan evaluasi. Untuk menentukan kemajuan yang dicapai maka harus ada kriteria (patokan) yang mengacu pada tujuan yang telah ditentukan sehingga dapat diketahui seberapa besar pengaruh strategi beajar mengajar terhadap keberhasilan belajar siswa.

Pada pembelajaran tari melalui media audio visual ini penilaian yang digunakan adalah penilaian

psikomotorik

(keterampilan).

Indikator

penilaiannya adalah wiraga ( Kesesuaian gerak dengan teknik yang benar), wirama (kesesuaian gerak dengan tempo musik iringan), wirasa (mampu menghayati tarian lewat ekspresi wajah dan mampu mengatur emosi diri). Pada unsur wiraga (wrg) penilaian yang dicapai adalah 50\%, pada unsur wirama (wrm) penilaian yang dicapai $30 \%$, dan pada penilaian wirasa (wrs) $20 \%$. Penilaian pada unsur wiraga lebih ditekankan, karena dalam suatu pembelajaran tari, gerak lah yang paling diutamanakan, sehingga unsur wiraga yang menjadi penilaian yang lebih besar. Skor penilaian penguasaan tari Sitalasari tidak dengan psikomotorik (keterampilan) saja, tetapi aspek penilaian sikap dalam tari Sitalasari juga dilakukan. Indikator penilaiannya adalah: (1) Kerjasama, (2) Keaktifan, (3) Disiplin, (4) Tanggung jawab. 4 aspek penilaian sikap ini juga dilakukan pada proses pembelajaran tari Sitalasari melalui media audio visual ini. 


\section{PENUTUP}

\section{Kesimpulan}

Setelah dilakukan pengamatan dan analisis dalam penelitian ini maka diperoleh kesimpulan sebagai berikut :

1. Penggunaan media audio visual pada pelajaran seni budaya sub pokok atau mata pelajaran seni tari dengan materi tari Sitalasaridapat meningkatkan hasil belajar seni tari siswa.

2. Nilai pembelajaran seni tari siswa meningkat dengan adanya media audio visual. Sebelum menggunakan media audio visual, nilai rata-rata siswa pada pembelajaran seni tari kecenderungan dibawah ratarata,tetapi dengan metode pengajaran menggunakan audio visual akhirnya dapat membantu. Oleh karena itu dengan audio visual anak-anak lebih mudah dalam proses pembelajaran tari. Dengan menggunakan media audio visual siswa mampu menari dengan teknik yang benar, menghapal setiap ragam gerak sitalasari dengan cepat, mengkordinasikan gerak antar bagian, menari dengan ketepatan tempo dengan musik, menari dengan ekspresi.

3. Mempermudah guru dalam proses belajar mengajar, dan menambah kreativitas guru dalam membuat media pembelajaran yang menarik.

\section{Saran}

Berdasarkan hasil penelitian dan kesimpulan, maka penulis menyampaikan beberapa saran sebagai berikut :

1. Kepada guru, diharapkan agar lebih kreatif dalam menentukan metode yang digunakan pada proses belajar mengajar seni tari. Diharapkan hendaknya guru mampu menentukan metode yang digunakan, dan mampu menggunakan strategi lain untuk menyampaikan teori maupun praktek tari, agar siswa lebih bersemangat dalam pembelajaran tari salah satunya dengan menggunakan media audio visual.

2. Bagi penulis selanjutnya yang ingin melakukan penelitian yang serupa diharapkan penelitian ini dapat menjadi bahan perbandingan atau refrensi yang bermanfaat untuk mendukung penelitian selanjutnya. 
Gesture

3. Pada penulis selanjutnya

DAFTAR PUSTAKA

disarankan untuk menggunakan media audio visual dalam meningkatkan hasil belajar siswa diluar sitalasaripada pelajaran seni tari.

Ahira,

Anne.

2012.

PengertianKontribusi. Bandung :Kencana

Ali, $\quad$ Muhammad. 2005.

KamusLengkapBahasa

Indonesia Modern.Jakarta

:PustakaAmani

Hadi, Y, Sumandiyo. (2002).

KajianTari, Yogyakarta:

Pustaka Book Publisher.

Hamalik. 2004. Media Pembelajaran. Yogyakarta: BalaiPustaka

Hidayat. 2007.

MetodePenelitianKuantitatif.

Jakarta

Kusumo.Jati.

2011.PengaruhStrategiPembe lajaran Peer Teaching TerhadapHasilBelajarMener apkanTeknikElektronika Analog dan Digital Dasar di SMK Dwitunggal

TanjungMorawa.Skripsi

Universitas Negeri Medan.

K.Suzanne, Langer 1997, Problems of Art, terjemahan F.X. Widyamanto, Bandung :AkademiSeniTari Indonesia 
Maryaeni.

2005.

MetodePenelitianKebudayaan

. Jakarta :BumiAksara

Munadi, Y. 2008. Media

Pembelajaran. Jakarta:

GaungPersada.

Nurwani SST M.Hum.2014. Bahan

Ajar Pengetahuan Seni Tari.

Medan: UNIMED PRESS

Rahayu. 2012. Penerapan Model

PembelajaranKooperatifTipe

Learning Together

TerhadapHasilBelajarSeniTa

riPadaSiswa-siswiKelas VIII

MTS

MiftahussalamMedanTahunA

jaran 2012/2013. Skripsi 